\title{
CONCEPTUAL STUDIES OF A FUEL-FLEXIBLE LOW-SWIRL COMBUSTION SYSTEM FOR THE GAS TURBINE IN CLEAN COAL POWER PLANTS
}

\author{
Kenneth O. Smith, Peter L. Therkelsen, David Littlejohn, Sy Ali and Robert K. Cheng \\ Lawrence Berkeley National Laboratory \\ One Cyclotron Road, MS:70-108B \\ Berkeley, California, USA \\ Email: rkcheng@lbl.gov
}

\begin{abstract}
This paper reports the results of preliminary analyses that show the feasibility of developing a fuel flexible (natural gas, syngas and high-hydrogen fuel) combustion system for IGCC gas turbines. Of particular interest is the use of Lawrence Berkeley National Laboratory's DLN low swirl combustion technology as the basis for the IGCC turbine combustor. Conceptual designs of the combustion system and the requirements for the fuel handling and delivery circuits are discussed.

The analyses show the feasibility of a multi-fuel, utilitysized, LSI-based, gas turbine engine. A conceptual design of the fuel injection system shows that dual parallel fuel circuits can provide range of gas turbine operation in a configuration consistent with low pollutant emissions. Additionally, several issues and challenges associated with the development of such a system, such as flashback and auto-ignition of the highhydrogen fuels, are outlined. [Keywords: Syngas, DLN, IGCC]
\end{abstract}

\section{NOMENCLATURE}

$\begin{array}{ll}\Delta \mathrm{P}_{\text {inj }} & \text { Fuel injection differential pressure } \\ \mathrm{HHF} & \text { High hydrogen fuel } \\ \text { LHV } & \text { Lower heating value } \\ \text { LSI } & \text { Low swirl injector } \\ \mathrm{MHF} & \text { Medium hydrogen fuel } \\ \mathrm{PIV} & \text { particle image velocimetry } \\ \mathrm{P}_{\mathrm{cd}} & \text { Compressor discharge pressure } \\ \mathrm{STP} & \text { Standard temperature and pressure } \\ \mathrm{S}_{\mathrm{T} \text {-LD }} & \text { Local displacement turbulent flame speed } \\ \mathrm{T}_{\mathrm{ad}} & \text { Adiabatic flame temperature } \\ \mathrm{T}_{\text {cd }} & \text { Compressor discharge temperature } \\ \mathrm{T}_{\mathrm{f}} & \text { Fuel temperature }\end{array}$

$\begin{array}{ll}\mathrm{T}_{\mathrm{pz}} & \text { Primary zone temperature } \\ \mathrm{U}_{0} & \text { Bulk flow velocity of the reactants } \\ \mathrm{WI} & \text { Wobbe index } \\ \mathrm{W}_{\mathrm{a}} & \text { Air flow rate } \\ \mathrm{W}_{\mathrm{f}} & \text { Fuel flow rate } \\ \gamma & \text { Specific gravity }\end{array}$

\section{INTRODUCTION}

Typically, industrial and utility-sized gas turbine engines operate with natural gas fuel. These gas turbines are specifically developed for pipeline quality natural gas and cannot tolerate large variations in the fuel composition. More modern gas turbines frequently employ lean premixed combustion also known as dry-low $\mathrm{NO}_{\mathrm{x}}$ (DLN) to limit exhaust emissions of $\mathrm{NO}_{\mathrm{x}}$, in contrast to earlier commercial gas turbines that employ non-premixed (diffusion flame) combustors. These low emission turbines are even more sensitive to fuel composition due to the need for more precise control of the combustion process.

There is considerable interest in the use of syngas, derived from gasified coal, as a primary fuel for large utility-sized gas turbines (> $100 \mathrm{MW}$ ) in Integrated Gasification Combined Cycle (IGCC) coal-based power plants. The use of syngas in commercial gas turbines will necessitate the design and development of modified or alternative combustion systems that can reliably burn this new fuel. These combustion systems will be required to provide the same low pollutant emission levels being achieved today with natural gas without compromising turbine durability or operability. In addition, a development goal is to allow smooth transitions, without flaring, between natural gas and either unshifted syngas (having a medium hydrogen content) and/or shifted syngas (with a high hydrogen content). Unshifted syngas is characterized by nearly equal 
percentages of hydrogen and $\mathrm{CO}$, with low levels of $\mathrm{CO}_{2}$. If this gas is subjected to a water-gas shift reaction, a high hydrogen fuel is created, containing 80-90\% hydrogen with little $\mathrm{CO}$ or $\mathrm{CO}_{2}$. The high hydrogen fuel can be further purified to nearly $100 \%$ hydrogen if desired. Specific compositions for both unshifted and shifted syngases depend upon initial coal composition, gasifier type, and gasifier operating conditions.

\section{BACKGROUND AND OBJECTIVE}

The Low Swirl Injector (LSI) is a lean premixed combustion device developed at LBNL. It has the potential to meet the outlined requirements with natural gas and the two categories of syngas fuels [1]. LSI burners are in use in commercial heating applications and have been developed for microturbines and medium-sized gas turbine engines using natural gas [2]. The burners have proven to be robust and provide ultra- low emissions in these applications. In addition, laboratory tests have shown that the fundamental operating principle of the LSI provides not only fuel flexibility but also smooth transitions between various fuels. Laboratory results obtained at simulated gas turbine conditions using simulated coal-based syngases [3] and natural gas and hydrogen blended fuels [4] show that the LSI does not require any hardware change to operate with these different fuels.

The LSI swirler [5] is a key component of the technology. It is designed to produce a divergent flow at the discharge plane of the injector. Its diverging flow pattern is characterized by a linear decay of the axial velocity away from the discharge plane. It allows the premixed turbulent flame to stabilize at a position where the local air velocity is equal and opposite to the local turbulent displacement flame speed, $\mathrm{S}_{\mathrm{T}-\mathrm{LD}}$. The result is a lifted flame that stabilizes downstream of the injector exit. The distance between the injector exit plane and the flame is dependent upon the decay rate of the axial velocity (a function of the LSI swirl number) and $\mathrm{S}_{\mathrm{T}-\mathrm{LD}}$ (a property of the fuel type, equivalence ratio, turbulence, and inlet conditions).

When operating with $\mathrm{CH}_{4}$, laboratory experiments at atmospheric conditions show the LSI flame position to be invariant with bulk velocity $\left(\mathrm{U}_{0}\right)$ except when flashback is imminent $\left(\mathrm{U}_{0}<3 \mathrm{~m} / \mathrm{s}(9.8 \mathrm{ft} / \mathrm{s})\right)$. The flame position is also insensitive to the fuel/air equivalence ratio, $\phi$, when $\mathrm{U}_{0}>3 \mathrm{~m} / \mathrm{s}$ $(9.8 \mathrm{ft} / \mathrm{s})$. These characteristics can be explained by means of an analytical model describing the coupling between the selfsimilar characteristics of the divergent flow ${ }^{1}$ and the linear correlation of $S_{\mathrm{T}-\mathrm{LD}}$ with the turbulent fluctuation $\mathrm{u}^{2}$ [6]. Under simulated gas turbine conditions, the experiments also show that the flame position remains invariant at $10<\mathrm{U}_{0}<85 \mathrm{~m} / \mathrm{s}(33<$ $\mathrm{U}_{0}<279 \mathrm{ft} / \mathrm{s}$ ) and is not significantly different than at

\footnotetext{
1 Self similar behavior of the divergent flow is indicated by the normalized axial velocity decay rate being constant over a range of $\mathrm{U}_{0}$

${ }^{2} \mathrm{~S}_{\mathrm{T}-\mathrm{LD}}$ is one of four different definitions of the turbulent flame speed [6]. The linear correlation trend of $\mathrm{S}_{\mathrm{T}-\mathrm{LD}}$ with $\mathrm{u}$ ' is observed only at the axis of the LSI burners
}

atmospheric conditions. The basic LSI flow/flame coupling process is not affected by the initial temperature and pressure.

Further tests, however, show that fuel hydrogen concentration does affect the LSI flame position. Transitioning from natural gas to $\mathrm{H}_{2}$ results in the flame shifting closer to the injector [4]. As shown by the analytical model, the upstream shift is a consequence of the increase in $S_{T-L D}$ due to the high reactivity of $\mathrm{H}_{2}$. These laboratory results show that the basic design of the LSI is amenable to fuel-flexible operation, and the variations in fuel composition expected during IGCC operation will not affect the basic combustion process of the LSI.

The objective of this study described below was to show the feasibility of an LSI-based fuel-flexible combustion system for IGCC gas turbines. The properties and combustion characteristics of three specific fuels: natural gas, unshifted sygas, and a high hydrogen shifted fuel, are considered in developing the basic layout of the fuel handling and delivery circuit. A conceptual design of the LSI for a typical F-frame gas turbine combustor is proposed. The technical and engineering challenges associated with the development of such a system are also outlined.

\section{FUELS ANALYSIS}

The two coal-derived fuels being considered in our study, unshifted syngas (medium hydrogen fuel, MHF) and shifted syngas (high hydrogen fuel HHF), have no absolute defined molecular compositions. Nominally, hydrogen concentrations of MHF and HHF range from 20 to $50 \%$ and 50 to $100 \%$, respectively. For our analyses, the fuel gas compositions listed in Table 1 were used to represent typical MHF and HHF. The physical and combustion properties of these fuels are compared in Table 2 with those of natural gas and pure hydrogen.

Also listed in Table 2 are the Wobbe index values that indicate the potential interchangeability of fuel gases for a single fuel delivery/fuel injection system. The Wobbe index values, however, do not account for fuel effects on factors such as emissions, flashback, auto-ignition, flame stability, or combustor pattern factor. Wobbe index is calculated as:

$$
W I=\frac{L H V_{v o l}}{\sqrt{\gamma}} \quad \text { Eq. } 1
$$

Eq. 1 defines one of several possible variations of the Wobbe index. Modified Wobbe index definitions can include temperature, pressure and fuel system effective area terms. For the current assessment, Eq. 1 was deemed adequate for a comparative study of fuel interchangeability. 
Table 1: Fuel Gas Composition, Mole Percent

\begin{tabular}{|l|c|c|c|c|}
\hline & $\begin{array}{c}\text { Natural } \\
\text { Gas }\end{array}$ & Pure $\mathrm{H}_{2}$ & $\begin{array}{c}\text { Medium } \\
\mathrm{H}_{2}\end{array}$ & $\begin{array}{c}\text { High } \\
\mathrm{H}_{2}\end{array}$ \\
\hline $\mathrm{CH}_{4}$ & 97 & & & \\
\hline $\mathrm{H}_{2}$ & & 100 & 30 & 81 \\
\hline $\mathrm{CO}$ & & & 56 & 3 \\
\hline $\mathrm{CO}_{2}$ & & & 3 & 3 \\
\hline $\mathrm{N}_{2}$ & 3 & & 10 & 12 \\
\hline $\mathrm{H}_{2} \mathrm{O}$ & & & 1 & 1 \\
\hline
\end{tabular}

Table 2: Fuel Gas Properties

\begin{tabular}{|l|c|c|c|c|}
\hline & $\begin{array}{c}\text { Natural } \\
\text { Gas }\end{array}$ & Pure $\mathrm{H}_{2}$ & $\begin{array}{c}\text { Medium } \\
\mathrm{H}_{2}\end{array}$ & High $\mathrm{H}_{2}$ \\
\hline $\begin{array}{l}\text { Molecular } \\
\text { Weight } \\
-\mathrm{kg} / \mathrm{kmol}\end{array}$ & 16.4 & 2.0 & 20.6 & 7.3 \\
\hline $\begin{array}{l}\text { Specific Gravity } \\
-\gamma\end{array}$ & 0.54 & 0.07 & 0.71 & 0.25 \\
\hline $\begin{array}{l}\text { Density @ STP } \\
-\mathrm{kg} / \mathrm{m}^{3} \\
\left(\mathrm{lbm} / \mathrm{ft}^{3}\right)\end{array}$ & 0.65 & 0.08 & 0.86 & 0.30 \\
\hline $\begin{array}{l}\mathrm{LHV}-\mathrm{kJ} / \mathrm{kg} \\
(\mathrm{Btu} / \mathrm{lbm})\end{array}$ & $\begin{array}{c}47,450 \\
(20,400)\end{array}$ & $\begin{array}{c}120,580 \\
(51,840\end{array}$ & $\begin{array}{c}11,193 \\
(4,812)\end{array}$ & $\begin{array}{c}27,842 \\
(11,970)\end{array}$ \\
\hline $\begin{array}{l}\mathrm{LHV}-\mathrm{kJ} / \mathrm{m}^{3} \\
\left(\mathrm{Btu} / \mathrm{ft}^{3}\right)\end{array}$ & $\begin{array}{c}32,676 \\
(877)\end{array}$ & $\begin{array}{c}10,059 \\
(270)\end{array}$ & $\begin{array}{c}9,687 \\
(260)\end{array}$ & $\begin{array}{c}8,457 \\
(227)\end{array}$ \\
\hline $\begin{array}{l}\mathrm{Wobbe} \mathrm{Index} \mathrm{-} \\
\mathrm{MJ} / \mathrm{m}^{3} \\
\left(\mathrm{Btu} / \mathrm{ft}^{3}\right)\end{array}$ & $\begin{array}{c}44.2 \\
(1,186)\end{array}$ & $\begin{array}{c}38.3 \\
(1,028)\end{array}$ & $\begin{array}{c}11.4 \\
(306)\end{array}$ & $\begin{array}{c}17.0 \\
(456)\end{array}$ \\
\hline $\mathrm{T}_{\mathrm{ad}} \mathrm{STP}-\mathrm{K}(\mathrm{F})$ & 2,322 & 2,530 & 2,500 & 2,409 \\
& $(3,720)$ & $(4,094)$ & $(4,040)$ & $(3,876)$ \\
\hline
\end{tabular}
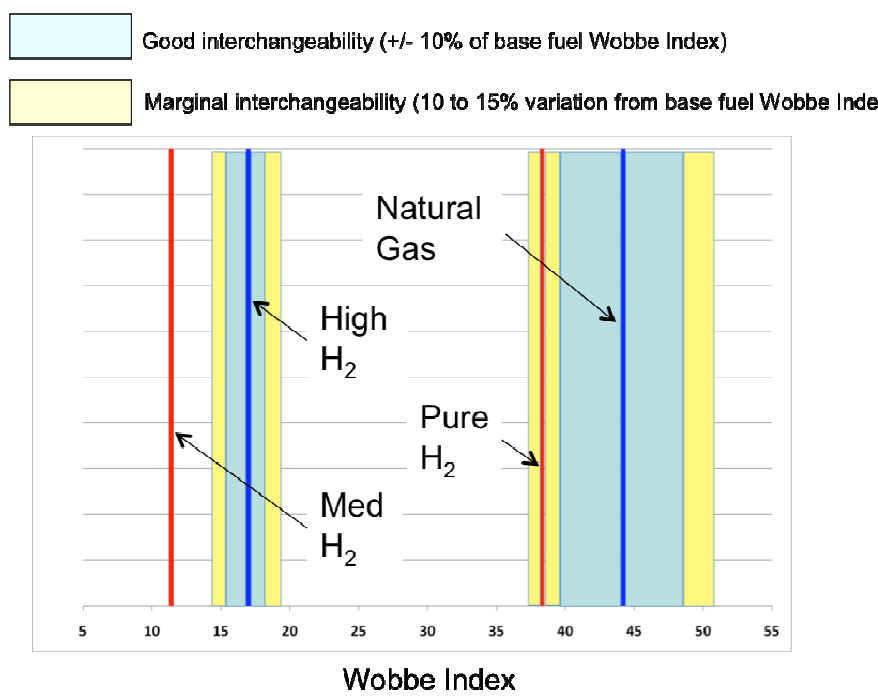

Figure 1: Wobbe Index Values for Fuels of Interest

\begin{tabular}{|l|c|c|c|c|}
\hline $\begin{array}{l}\text { Laminar Flame } \\
\begin{array}{l}\text { Speed }-\mathrm{cm} / \mathrm{s} \\
(\mathrm{in} / \mathrm{s})\end{array}\end{array}$ & $\begin{array}{c}39 \\
(15)\end{array}$ & $\begin{array}{c}204 \\
(80)\end{array}$ & $\begin{array}{c}77 \\
(30)\end{array}$ & $\begin{array}{c}188 \\
(74)\end{array}$ \\
\hline
\end{tabular}

The fuel injection system for a lean premixed gas turbine combustor is designed for a specific fuel with a characteristic Wobbe index. If an alternative fuel of significantly lower Wobbe index is used in the injection hardware, unacceptably high pressure drop will occur. In general, an alternative fuel is considered to be interchangeable (assuming a given injection system) when the Wobbe index of the alternative fuel is within $\pm 10 \%$ of the design value. Fuels with Wobbe indices falling within $\pm 15 \%$ are considered marginally interchangeable. Outside of $\pm 15 \%$, changes in injector hardware and control protocol are deemed necessary.

The calculated Wobbe indices for the four fuels of this study are plotted in Figure 1. Also shown are the $\pm 10 \%$ and $\pm 15 \%$ margins for natural gas and HHF. This figure shows that pure $\mathrm{H}_{2}$ is marginally interchangeable with natural gas but that the MHF and HHF fuels will not be interchangeable. Clearly, the MHF and HHF fuels, with much lower Wobbe indices, will require larger fuel injectors to maintain a constant fuel-side pressure drop.

The interchangeability of natural gas and hydrogen has been demonstrated in a small-scale gas turbine [7]. In that study, the injector hardware had been modified only to mitigate the effects associated with the highly reactive combustion properties of hydrogen that include high turbulent flame speed and short auto-ignition times. Other changes to alter bulk fuel flow through the injector were not needed as the Wobbe indices of pure hydrogen and natural gas fall within $15 \%$ of each other.

Figure 1 indicates that the Wobbe indices of the MHF and HHF are within $30 \%$ of each other. This relatively large difference in Wobbe index should not be taken to indicate a requirement for completely unique fuel injection hardware for each of the two fuels. As noted above, the specific fuel compositions and Wobbe indices of the MHF and the HHF will vary with the feedstock and the gasification process. In addition, the Wobbe indices will need to reflect any differences in fuel temperature and pressure. Thus, the $30 \%$ difference can be interpreted to show some potential, even if not optimal, for the MHF and the HHF to operate with the same or only moderately different fuel injection hardware.

The main implication of the analysis is that the same baseline design for an MHF LSI gas turbine injector could serve for an HHF fuel with only minor modifications. Conceptually, the final LSI injector would contain two fuel circuits: one for natural gas (and possibly hydrogen), and one for the specific hydrogen-containing fuel being generated on-site (either MHF or HHF or may be both).

\section{COMBUSTION SYSTEM CHARACTERISTICS}

A preliminary design study of a multi-fuel LSI combustion system was conducted for a representative F class, nominal 200 
MW, gas turbine. The design baseline was for MHF as it has the lowest Wobbe index and requires the largest mass fuel flow rate. The use of an MHF fuel system with natural gas or HHF will result in lower (thus acceptable) fuel-side pressure drop and improving efficiency over the MHF field gas turbines.

The combustor design is based on airflow of $453 \mathrm{~kg} / \mathrm{s}(999$ $\mathrm{lbm} / \mathrm{s}$ ) through the combustor and the first stage-cooled nozzle. A pressure ratio of 19 was assumed and used to calculate a compressor discharge temperature of $728 \mathrm{~K}(851 \mathrm{~F})$. Fuel inlet temperatures were assumed to be $366 \mathrm{~K}(199 \mathrm{~F})$ for the MHF and HHF and $458 \mathrm{~K}(365 \mathrm{~F})$ for natural gas. A first stage turbine rotor inlet temperature of $1,700 \mathrm{~K}(2,600 \mathrm{~F})$ was assumed. The MHF and HHF combustion properties were determined using a curve-fitting algorithm of the results from Chemkin premixed flame module calculations from Georgia Institute of Technology [8]. Fuel flow rates were calculated based on the assumed turbine inlet temperature. A primary zone airflow split of $84.4 \%$ was determined by setting the primary zone temperature to $1,839 \mathrm{~K}(2,850 \mathrm{~F})$ to control $\mathrm{NO}_{\mathrm{x}}$ emissions ${ }^{3}$. The combustor operating conditions were extrapolated for natural gas, MHF, and HHF using a fixed air flow split. Operating parameters are listed in Table 3 and show that the mass flow rates of MHF and HHF are significantly higher than the mass flow rate of natural gas.

Table 3: Combustor Operation Conditions

\begin{tabular}{|l|c|c|c|}
\hline & $\begin{array}{c}\text { Natural } \\
\text { Gas }\end{array}$ & $\begin{array}{c}\text { Medium } \\
\mathrm{H}_{2} \text { Fuel** }\end{array}$ & $\begin{array}{c}\text { High } \\
\mathrm{H}_{2} \text { Fuel }\end{array}$ \\
\hline $\mathrm{T}_{\mathrm{f}}-\mathrm{K}(\mathrm{F})$ & 458 & 366 & 366 \\
$(365)$ & $(199)$ & $(199)$ \\
\hline $\mathrm{T}_{\mathrm{pz}}-\mathrm{K}(\mathrm{F})$ & 1,853 & 1,839 & 1,842 \\
& $(2,876)$ & $(2,850)$ & $(2,856)$ \\
\hline $\mathrm{W}_{\mathrm{f}}-\mathrm{kg} / \mathrm{s}(\mathrm{lbm} / \mathrm{s})$ & 12.4 & 57.1 & 22.4 \\
& $(27.3)$ & $(126)$ & $(49.4)$ \\
\hline $\mathrm{PZ} \mathrm{fuel/air}$ & 0.032 & 0.149 & 0.059 \\
\hline $\begin{array}{l}\mathrm{W} \mathrm{a} \mathrm{pz}-\mathrm{kg} / \mathrm{s} \\
(\mathrm{lbm} / \mathrm{s})\end{array}$ & 382 & 382 & 382 \\
$(843)$ & $(843)$ & $(843)$ \\
\hline $\begin{array}{l}\text { Engine mass flow - } \\
\mathrm{kg} / \mathrm{s}(\mathrm{lbm} / \mathrm{s})\end{array}$ & 466 & 511 & 476 \\
\hline $\begin{array}{l}\text { Normalized mass } \\
\text { flow }\end{array}$ & $1,027)$ & $(1,126)$ & $(1,049)$ \\
\hline $\begin{array}{l}* * \text { used to establish primary zone air flow (unchanged for } \\
\text { other fuels) }\end{array}$ & 1.13 & 1.05 \\
\hline
\end{tabular}

\section{CONCEPTUAL FUEL INJECTOR DESIGN}

Several strategies can be identified for accommodating the use of MHF and HHF in fuel injectors designed for natural gas. If no modifications are made to the fuel injection system, the

${ }^{3}$ For this exercise, we assumed that $\mathrm{NO}_{\mathrm{x}}$ is a log-linear function of the adiabatic flame temperature, $\mathrm{T}_{\mathrm{ad}}$. This dependency has been observed in LSI laboratory experiment except for $\mathrm{HHF}$ at $\mathrm{T}_{\mathrm{ad}}<1,700 \mathrm{~K}[2,600 \mathrm{~F}]$ where $\mathrm{NO}_{\mathrm{x}}$ levels off at 1 ppm (@15\% $\mathrm{O}_{2}$ ) engine will operate at derated (reduced) power output at the design fuel pressure. This is undesirable from both the efficiency and output perspectives. A second strategy is the integration of additional fuel injectors into the combustion system. This approach has been adopted with conventional combustors to allow operation on low Btu gases. The large size of lean premixed injectors most likely precludes this approach. Instead, the preferred approach is a redesign of the lean premix injectors to provide larger flow passages for the MHF and HHF and possible modifications to the fuel delivery system, allowing for higher fuel inlet pressures. The large mass flow of MHF requires higher inlet pressure than either natural gas of HHF. This would require higher fuel inlet pressure, a parasitic loss to the engine.

As proposed earlier, dual parallel fuel circuits in an LSI module can provide the flexibility for multi-fuel operation, while preserving the power output of the turbine. A conceptual LSI design was developed to meet this goal using the data in Tables 2 and 3. Specific issues addressed in the design included:

- Incorporating new injectors with minimum changes to the existing lean premixed combustor geometry.

- Accommodating the higher risk of flashback and autoignition with MHF and HHF.

- Maintaining an acceptable fuel pressure drop with MHF and HHF.

- Continuing to meet single digit $\mathrm{NO}_{\mathrm{x}}$ emissions standards.

- Having the ability to co-burn natural gas and either MHF or HHF during fuel transfer and gasifier startup. The ultimate goal is to avoid flaring of syngas during engine transient operation.

- Maximizing design commonality between medium and high hydrogen injection systems.

Most lean premixed, F class gas turbines employ multiple combustion cans, each containing several fuel injectors. The analysis of the LSI system was based on this type of $\mathrm{F}$ class engine containing $35.6-63.5 \mathrm{~cm}(14-25$ in) diameter cans. The preliminary design adopted a configuration with five injectors placed equidistant from the axis of the can with spacing for a central diffusion pilot injector. The pilot is used during start up, fuel transition, and for mitigating any combustion stability issues. Figure 2 illustrates the basic layout of the five LSIs in one combustor can. Based on our estimated air consumption of $453 \mathrm{~kg} / \mathrm{s}(999 \mathrm{lbm} / \mathrm{s})$ the diameter of each LSI is estimated to be $12.7 \mathrm{~cm}(5 \mathrm{in})$. 


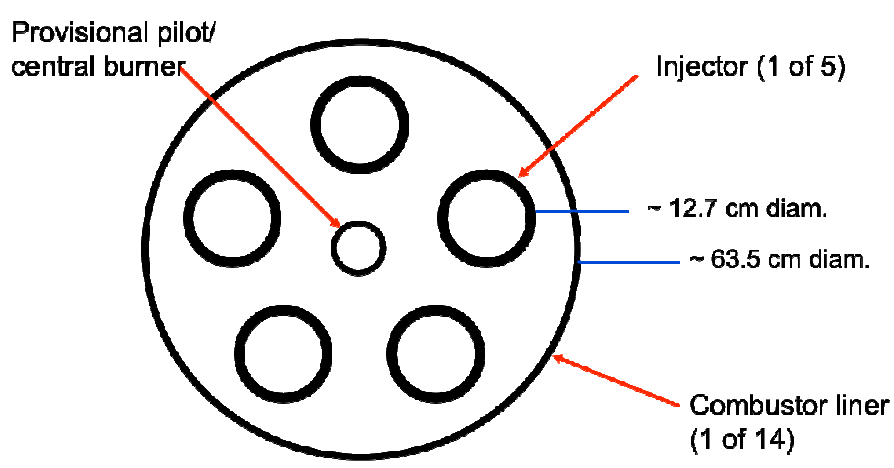

Figure 2: Conceptual Illustration of Injector Layout for Single Can Combustor

It is common for lean premix natural gas injectors to deliver fuel to a swirling air stream via axial spokes. Injection orifices along these spokes ensure an even distribution of fuel to the turbulent airflow. Fuel flow, fuel pressure drop and fuel distribution are factors used to determine the number, size and placement of the orifices in the spokes. In addition, the number and placement of fuel spokes is a trade-off between good initial fuel distribution and airside pressure drop. Calculations of these characteristics were performed based upon fundamental gas turbine engineering equations. As discussed above, two sets of fuel spokes are proposed for the LSI system. Each fuel spoke set is fed by an individual fuel circuit. One circuit/spoke set is for natural gas (and pure hydrogen if desired) and the other is the syngas fuels. Fuel feed line and spoke/orifice dimensions were calculated for both the natural gas and syngas fuel circuits. These dimensions, as well as operating conditions, are listed in Table 4 for each injector.

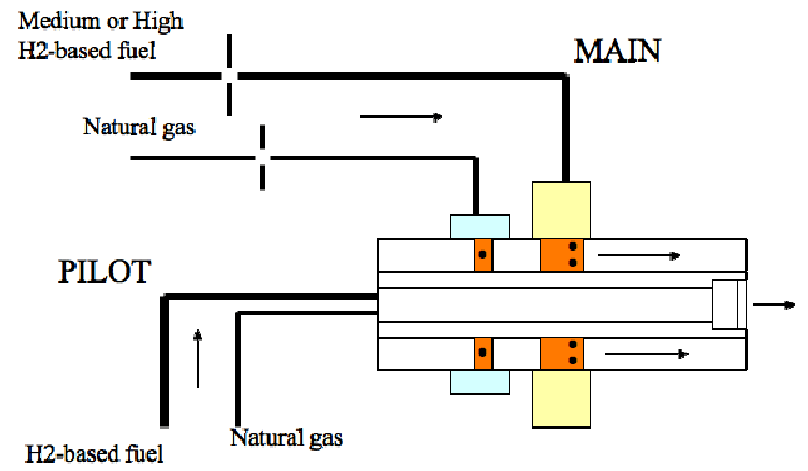

Figure 3: Conceptual Illustration of Dual Fuel Gas Injector

Table 4: Conceptual Natural Gas and Hydrogen Containing Fuel Geometries and Flow Characteristics Per Injector

\begin{tabular}{|l|c|c|c|}
\hline & $\begin{array}{c}\text { Natural } \\
\text { Gas }\end{array}$ & $\begin{array}{c}\text { Medium } \\
\mathrm{H}_{2} \text { Fuel }\end{array}$ & $\begin{array}{c}\text { High } \\
\mathrm{H}_{2} \text { Fuel }\end{array}$ \\
\hline Number of Injectors & 70 & 70 & 70 \\
\hline $\mathrm{W}_{\mathrm{f}}-\mathrm{kg} / \mathrm{min}(\mathrm{lbm} / \mathrm{min})$ & 10.5 & 49.0 & 19.2 \\
& $(23.2)$ & $(108)$ & $(42.3)$ \\
\hline $\mathrm{T}_{\mathrm{f}}-\mathrm{K}(\mathrm{F})$ & 458 & 366 & 366 \\
& $(365)$ & $(199)$ & $(199)$ \\
\hline
\end{tabular}

\begin{tabular}{|l|c|c|c|}
\hline Air: $\mathrm{P}_{\mathrm{cd}}-\mathrm{kPa}(\mathrm{atm})$ & $\begin{array}{c}1,925 \\
(19)\end{array}$ & $\begin{array}{c}1,925 \\
(19)\end{array}$ & $\begin{array}{c}1,925 \\
(19)\end{array}$ \\
\hline Air: $\mathrm{T}_{\mathrm{cd}}-\mathrm{K}(\mathrm{F})$ & 727 & 727 & 727 \\
& $(849)$ & $(849)$ & $(849)$ \\
\hline $\mathrm{W}_{\mathrm{a}} \mathrm{pz}-\mathrm{kg} / \mathrm{s}(\mathrm{lbm} / \mathrm{s})$ & 5.4 & 5.4 & 5.4 \\
& $(12)$ & $(12)$ & $(12)$ \\
\hline$\Delta \mathrm{P}_{\text {inj }}-\mathrm{kPa}(\mathrm{atm})$ & 86 & 138 & 55 \\
& $(0.85)$ & $(1.36)$ & $(0.54)$ \\
\hline Orifice count & 300 & 300 & 300 \\
\hline $\begin{array}{l}\text { Orifice diameter }-\mathrm{mm} \\
\text { (in) }\end{array}$ & 1.11 & 1.9 & 1.9 \\
\hline $\begin{array}{l}\text { Fuel line diameter - cm } \\
\text { (in) }\end{array}$ & $(0.044)$ & $(0.075)$ & $(0.075)$ \\
\hline & $(0.75)$ & 3.2 & 3.2 \\
$(1.26)$ & $(1.26)$ \\
\hline
\end{tabular}

The basic layout of a multi-fuel LSI is shown in Figure 3. The fuel injectors for the syngas fuels are positioned closer to the injector exit to mitigate auto-ignition risk. Shock tube experiments indicate fuels with compositions similar to that of MHF are characterized by short auto-ignition times. Ignition delay time of $80 \mathrm{msec}$ was measured for conditions of $\phi=0.3$, $2,026 \mathrm{kPa}(20 \mathrm{~atm})$, and inlet temperature of $727 \mathrm{~K}(849 \mathrm{~F})$ [9]. Ignition delay time is highly dependent upon the percentage of hydrogen in the fuel stock and inlet temperature [10]. Therefore, the ignition delay time for the HHF are expected to be much shorter than $80 \mathrm{msec}$. To ensure injector and turbine durability a residence time of $5 \mathrm{msec}$ was adopted for the LSI design.

The $5 \mathrm{msec}$ residence time criteria would suggest a maximum premixing length of $24.6 \mathrm{~cm}$ was acceptable, assuming that the flow within the injector is everywhere equal to the bulk flow velocity $\mathrm{U}_{0}$. In reality, particle image velocimetry (PIV) measurements obtained inside and outside the LSI nozzle show that the radial distribution of the velocity across the LSI has a minimum at the central axis of only about $60 \%$ of $\mathrm{U}_{0}$. Additionally, the flow decelerates linearly away from the LSI exit and enters the flame at a velocity of lower than $30 \%$ of $\mathrm{U}_{0}$. The flow deceleration suggests that the maximum allowable premixing distance is significantly lower.

Because the LSI flowfield is self-similar, the PIV data measured in a smaller LSI of $5.6 \mathrm{~cm}$ diameter [4] can be used to obtain a more accurate estimate of the premixing length. Integration of the PIV axial velocity profile from an estimated fuel injection point to the leading edge position of the flame brush showed that the $5 \mathrm{msec}$ residence time for LSIs of 12.7 $\mathrm{cm}$ diameter allows a maximum premixing length of $10 \mathrm{~cm}$. This premixing length is slightly smaller than the injector diameter but is within the LSI design guideline specifying that the swirler should be recessed at a minimum of about one diameter from the exit. Additionally, the $10 \mathrm{~cm}$ premixing distance is relatively short and suggests the need to embed the injectors for the syngas fuels into the swirl vanes. Otherwise the flow disturbances created by the injection spokes may disrupt the flow exiting the swirler. 
Autoignition delay times for methane at gas turbine conditions are not considered to be a major concern as they are longer than those of the MHF and HHF. Interpolating upon results from recent work, at turbine operating conditions a residence time of 1.6 seconds is allowable for natural gas [11]. This long time allows for the extra injection length required of having a natural gas fuel circuit upstream of the syngas circuit.

\section{OPERATIONAL CONSIDERATIONS}

The LSI with two fuel circuits (one for natural gas and one for hydrogen-containing syngas) and a central multi-fuel pilot provides considerable fueling flexibility. As the secondary fuel, natural gas can be used during engine start up and when the gasifier is offline. Additionally, natural gas can be blended with the syngas produced during gasifier start up and shut down, thus removing the need for fuel flaring. The central diffusion pilot burner can be fueled with natural gas when starting the gas turbine and while transitioning to syngas operation. The pilot, fueled with natural gas or syngas, can be used to ensure combustion stability, as is typical with low emissions engines today, although with some impact on emissions reduction. Additionally, pure hydrogen can be used in the natural gas circuit if available as the two fuels have similar Wobbe indices.

\section{CONCLUSION AND CHALLENGES}

The preliminary analyses conducted demonstrate the feasibility of a multi-fuel (natural gas and coal-derived syngas), utility-sized, LSI gas turbine. Preliminary conceptual design of the fuel injection system shows that dual parallel fuel circuits provide for full range of turbine operation in a configuration consistent with low pollutant emissions. Refinement of the injector design needs to be conducted once a candidate gas turbine has been selected for prototype development.

Additionally, a number of issues and potential challenges will need further attention as design development efforts continue:

- Combustor and first stage cooling: The three fuels of interest will produce somewhat different product gas temperatures as well as product gas compositions in the combustor primary zone and entering the first stage of the gas turbine. Consequently, the combustor liner and the first stage vanes and blades may experience different heat transfer rates with different fuels. Proper cooling airflow rates and air distribution over the liner surface and in the first stage stator and rotor need to be determined.

- Fuel injector length: Minimization of the fuel residence time within the injector is necessary to avoid damage due to autoignition. However, short residence times following fuel injection may result in degraded fuel/air mixing. Near homogeneous mixing is required to minimize pollutant emissions as well as to meet pattern factor specifications.
- Fuel spoke design: Optimization of the number, placement, and size of fuel spokes and fuel orifices must be conducted. Non-optimized placement of fuel spokes have been shown to create excessive pressure drops across the injector and undesired flow splits within the injector. Proper fuel orifice location and size will promote rapid and homogeneous fuel/air mixing.

- Combustor volume: Natural gas lean premixed combustors employ larger combustors than their diffusion flame counterparts. This larger volume ensures full $\mathrm{CO}$ to $\mathrm{CO}_{2}$ conversion. Hydrogen containing fuels burn faster than natural gas. To limit $\mathrm{NO}_{x}$ formation, smaller combustors may be advantageous with these fast burning fuels. Combustor volume will need to balance the need for extended residence time for $\mathrm{CO}$ burnout and limited residence time to limit $\mathrm{NO}_{\mathrm{x}}$ formation across the range of fuels to be burned.

- Acoustic oscillations: The potential for generating undesirable acoustic pressure oscillations when using and LSI system in a utility-sized gas turbine is unknown. Widening of the engine fuel specifications to include hydrogen-based fuels may increase the potential for unacceptably high pressure fluctuations.

- Large mass flow: Increased flow through the turbine section will occur due to the higher fuel mass flows associated with hydrogen-containing fuels. The possibility of gas turbine compressor surge exists and will need to be examined for the selected gas turbine.

- Natural gas fuel circuit transition: Pure hydrogen gas has been shown to be interchangeable with natural gas, thus, the natural gas fuel circuit can deliver both fuels. However, if "ultra high" hydrogen syngas is used instead of pure hydrogen, the interchangeability of the fuel with natural gas degrades as hydrogen content decreases. Injection of such a fuel through the natural gas circuit will result in excessively high fuel pressure drop. Significant redesigns of the fuel and combustion systems are called for. A cost-benefit analysis is necessary to establish the optimum system hydrogen concentration level.

\section{ACKNOWLEDGMENTS}

This research was supported by U.S. Department of Energy, National Energy Technology Laboratory of the Office of Fossil Energy under contract No. DE-AC02-05CH11231.

\section{REFERENCES}

[1] Cheng, R. K., 2006, DOE Gas Turbine Handbook, Low Swirl Combustion.

[2] Nazeer, W. A., Smith, K. O., Sheppard, P., Cheng, R. K., and Littlejohn, D., 2006, "Full Scale Testing of a Low Swirl Fuel Injector Concept for Ultra-Low Nox Gas Turbine 
Combustion Systems," T. Lieuwen, eds., Barcelona, Spain, GT2006-90150.

[3] Littlejohn, D., Cheng, R. K., Noble, D. R., and Lieuwen, T., 2010, "Laboratory Investivations of Low-Swirl Injector Operating with Syngases," Journal of Engineering for Gas Turbines and Power, 132(1), pp. 011502-011510.

[4] Cheng, R. K., Littlejohn, D., Strakey, P., and Sidwell, T., 2009, "Laboratory Investigations of Low-Swirl Injectors with

$\mathrm{H} 2$ and $\mathrm{Ch} 4$ at Gas Turbine Conditions," Proc. Comb. Inst., 32, pp. 3001-3009.

[5] Cheng, R. K., Yegian, D. T., Miyasato, M. M., Samuelsen, G. S., Pellizzari, R., Loftus, P., and Benson, C., 2000, "Scaling and Development of Low-Swirl Burners for Low-Emission Furnaces and Boilers," Proc. Comb. Inst., 28(1), pp. 13051313.

[6] Cheng, R. K., and Littlejohn, D., 2008, "Laboratory Study of Premixed H2-Air \& H2-N2-Air Flames in a Low-Swirl Injector for Ultra-Low Emissions Gas Turbines," Journal of Engineering for Gas Turbines and Power, 130, pp. 3150331511.

[7] Therkelsen, P., Werts, T., Mcdonell, V., and Samuelsen, S., 2009, "Analysis of Nox Formation in a Hydrogen-Fueled Gas Turbine Engine," Journal of Engineering for Gas Turbines and Power, 131(3), pp. 031507-10.

[8] Zhang, Q., Noble, D. R., Meyers, A., Xu, K., and Lieuwen, T., 2005, "Characterization of Fuel Composition Effects in $\mathrm{H}_{2} / \mathrm{Co} / \mathrm{Ch}_{4}$ Mixtures Upon Lean Blowout," eds., Reno, NV, GT2005-68907.

[9] Wolk, R. H., 2007, "Proceedings of the Workshop on Hydrogen Comubstion in Turbines," Technical Report No. Washington DC.

[10] Cheng, R. K., and Oppenheim, A. K., 1984, "Auto-Ignition in Methane-Hydrogen Mixtures," Combustion and Flame, 58(2), pp. 125.

[11] Beerer, D. J., and Mcdonell, V., 2009, "An Experimental and Kinetic Study of Alkane Autoignition at High Pressure and Intermediate Temperatures," Western Section of the Combustion Insititue, Fall Meeting, Irvine, CA. 